\title{
Pemanfaatan Batu Gunung Pasapak Kecamatan Bambang Kabupaten Mamasa sebagai Agregat Campuran Laston WC
}

\author{
Roy Cristian Ponglabba*1, Rais Rachman*2, Alpius ${ }^{* 3}$ \\ ${ }^{* 1}$ Mahasiswa Program Studi Teknik Sipil, Universitas Kristen Indonesia Paulus, Makassar, Indonesia \\ royponglabba21@gmail.com \\ ${ }^{* 2,3}$ Dosen Program Studi Teknik Sipil, Universitas Kristen Indonesia Paulus, Makassar, Indonesia \\ rais.rachman@gmail.com dan alpiusnini@gmail.com
}

\begin{abstract}
ABSTRAK
Penelitian ini membahas tentang campuran laston WC dengan memanfaatkan sumber daya alam berupa batu gunung yang berasal dari Pasapak Kecamatan Bambang Kabupaten Mamasa sebagai agregat dalam campuran. Penelitian ini dilakukan di Laboratorium Jalan dan Aspal Universitas Kristen Indonesia Paulus Makassar. Metodologi pada penelitian ini yaitu pemeriksaan karakteristik agregat, karakteristik aspal dan berat jenis Filler. Setelah serangkaian pemeriksaan karakteristik dilakukan, maka dilanjutkan dengan rancangan komposisi campuran dan pembuatan benda uji laston WC. Benda Uji laston WC kemudian diuji melalui pengujian Marshall konvensional untuk memperoleh karakteristik dari campuran meliputi Stabilitas, Flow, VMA, VIM dan VFB. Setelah diketahui karakteristik campuran, selanjutnya adalah pembuatan benda uji kadar aspal optimum (KAO) dimana KAO untuk campuran laston WC ditentukan berdasarkan nilai stabilitas tertinggi. Benda Uji KAO kemudian diuji melalui pengujian Marshall Immersion untuk memperoleh nilai Stabilitas Marshall Sisa. Hasil dari penelitian ini diperoleh karakteristik campuran laston WC dengan kadar aspal 5,50 $\%, 6,00 \%, 6,50 \%, 7,00 \%, 7,50 \%$ dan Stabilitas Marshall Sisa (SMS) sebesar 97,24\% memenuhi Spesifikasi Umum Bina Marga 2018.
\end{abstract}

Kata kunci : Karakteristik agregat, Komposisi LASTON WC, Marshall Test

\begin{abstract}
This study discusses a mixture of laston WC by utilizing natural resources in the form of mountain rocks from Pasapak, Bambang District, Mamasa Regency as an aggregate in the mixture. This research was conducted at the Road and Asphalt Laboratory of Paulus Makassar Christian University. The methodology in this study is the examination of aggregate characteristics, asphalt characteristics and density of fillers. After a series of characteristic checks were carried out, it was followed by the design of the mixture composition and the manufacture of the laston WC specimen. The laston WC specimen is then tested through conventional Marshall testing to obtain the characteristics of the mixture, which includes stability, flow, VMA, VIM and VFB. After knowing the characteristics of the mixture, the next step is to manufacture the optimum asphalt content test specimen (KAO) where KAO for the laston WC mixture is determined based on the highest stability value. The KAO specimen was then tested through the Marshall Immersion test to obtain the value of the remaining Marshall Stability. The results of this study obtained the characteristics of the laston WC mixture with asphalt content of $5.50 \%, 6.00 \%, 6.50 \%, 7.00 \%, 7.50 \%$ and the remaining Marshall Stability (SMS) of 97.24\% meets the specifications. General Bina Marga 2018.
\end{abstract}

\section{Keywords: Aggregate Characteristics, LASTON WC Composition, Marshall Test}

\section{PENDAHULUAN}

Pembangunan prasarana transportasi di dalam kota maupun di luar kota mengakibatkan meningkatnya kebutuhan penggunaan agregat. Untuk memenuhi kebutuhan agregat untuk prasarana transportasi maka perlu memanfaatkan sumber daya alam yang ada di sekitar lokasi seoptimal mungkin. Semakin banyak penggunaan agregat pada lapis perkerasan jalan maka biaya yang diperlukan banyak biaya untuk pembangunan maupun pemeliharaan jalan. Agregat harus cukup kuat untuk menahan beban kendaraan yang diterimanya. Mengingat jalan yang ada pada umumnya sebelum mencapai 
Paulus Civil Engineering Journal

Jurnal Teknik Sipil UKI-Paulus Makassar https://doi.org/10.52722/pcej.v3i2.3220

umur rencana telah mengalami kerusakan yang diakibatkan oleh beban kendaraan, air, pelaksanaan konstruksi yang tidak sesuai spesefikasi dan lain sebagainya. Oleh karena itu cepat mengalami kerusakan dan memerlukan perbaikan-perbaikan pada lapis permukaan, demikian pula jalan baru.

Untuk menghasilkan campuran beraspal yang memenuhi standar spesifikasi sesuai fungsinya, proporsi penggunaan bahan perkerasan beraspal harus direncanakan dengan baik. Agar mendapatkan campuran beraspal yang baik maka perlu dilakukan pemeriksaan/pengujian di Laboratorium terlebih dahulu. Berdasarkan himbauan Kementrian Pekerjaan Umum Perumahan Rakyat (PUPR) mendorong untuk menggunakan agregat di sekitar lokasi pekerjaan jalan. Belum maksimal penggunaannya, karena sampai saat ini penggunaan material Sungai Seriti hanya digunakan untuk bahan pembangunan rumah tinggal dan bahan timbunan. Dalam pembangunan perkerasan jalan di Kecamatan Lamasi Timur selama dilakukan untuk mengurangi biaya konstruksi maka agregat yang digunakan diperoleh dari sekitar lokasi pekerjaan. Dengan memperhatikan pemakaian agregat untuk pembangunan perkerasan jalan maupun untuk lapis permukaan di Kecamatan Lamasi Timur Kabupaten Luwu belum maksimal penggunaannya dikarenakan belum ada Laboratorium untuk meneliti kualitas agregat.

Berbagai penelitian yang pernah dilakukan untuk menguji pemanfaatan material local sebagai bahan perkerasan jalan antara lain Alloi dkk (2020), menelitinti tentang pemanfaatan agregat sungai wanggar kabupaten nabire sebagai bahan campuran AC-WC dan AC-BC [1]. Sosang dkk (2020) meneliti tentang pemanfaatan agregat sungai mawa kecamatan cendana dalam campuran AC-WC [2]. Rachman (2020) meneliti tentang pemanfaatan batu gunung bottomale toraja utara sebagai campuran Laston [3]. Irfan dkk (2020) pemanfaatan Batu Gunung Ambeso pada campuran AC-Base [4]. Salmon dkk (2020) meneliti tentang pemanfaatan Batu Gunung Posi'padang Balla Kabupaten Mamasa sebagai campuran AC-BC [5]. Palimbunga dkk (2020) meneliti tentang penggunaan agregat Sungai Batu Tiakka' dalam campuran AC-BC [6]. Sandabunga dkk (2020) meneliti tentang
Volume 3 No.2, Juni 2021

e-ISSN 2775-4529

p-ISSN 2775-8613 karakteristik campuran SMA Kasar menggunakan Batu Sungai Sa'dan Kecamatan Sesean Toraja Utara [7]. Jansen dkk (2020) pemanfaatan Batu Sungai Sa'dan Toraja Utara sebagai campuran Stone Matrix Asphalt Halus [8]. Selain penelitian tentang penggunaan material local beberapa peneliti yang meneliti tentang karakteristik campuran AC-Base antara lain Rachman (2019) meneliti tentang Karakteristik Campuran HRS BASE Menggunakan Bubuk Dolomit Sebagai Filler [9]. Tandibua dkk (2020) meneliti tentang Study of Laston BC Durability and Permeability Using Coconut Shell Addition Materials [10]. Randelabi dkk (2020) meneliti tentang pengujian karakteristik campuran HRS-Base menggunakan LGA sebagai pengganti aspal minyak [11].

Tujuan penelitian ini menguji pemanfaatan batu dari Sungai Seriti Kabupaten Luwu sebagai agregat campuran Laston Lapis Pondasi (ACBase) dengan menguji karakteristik agregat dan karakteristik campuran.

\section{METODE PENELITIAN}

\section{Lokasi pengambilan material}

Lokasi pengambilan material di Sungai Seriti Desa Seriti Kecamatan Lamasi Timur Kabupaten Luwu. Penyebaran material pada sungai ini sepenjang $1 \mathrm{Km}$ dan mengambil sampel dengan interval jarak $200 \mathrm{~m}$.

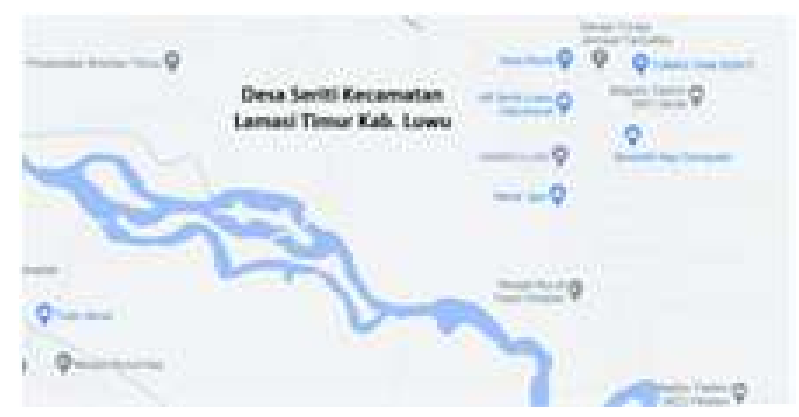

Gambar 1. Lokasi Pengambilan Material

\section{Pemeriksaan Karakteristik Agregat}

Pemeriksaan agregat didasarkan pada spesifikasi Bina Marga 2018 [12]. Pedoman pemeriksaan seperti pada tabel 1.

Tabel 1. Pedoman Karakteristik Agregat 
Paulus Civil Engineering Journal

Jurnal Teknik Sipil UKI-Paulus Makassar

https://doi.org/10.52722/pcej.v3i2.3220

\begin{tabular}{l|c}
\hline \multicolumn{1}{c|}{ Karakteristik } & Standar pengujian \\
\hline Analisa Saringan & SNI ASTM C136 2012 \\
\hline $\begin{array}{l}\text { Pemeriksaan Berat Jenis dan } \\
\text { Absorbsi Agregat Kasar }\end{array}$ & SNI 1969: 2016 \\
\hline $\begin{array}{l}\text { Berat Jenis dan Absorbsi } \\
\text { Agregat Halus }\end{array}$ & SNi 1970: 2016 \\
\hline Nilai Setara Pasir & SNI 03 4428 1997 \\
\hline Keausan & SNI 2417 2008 \\
\hline Partikel Pipih dan lonjong & ASTM D 4791 10 \\
\hline $\begin{array}{l}\text { Kelekatan Agregat Terhadap } \\
\text { Aspal }\end{array}$ & SNI 2439 2011 \\
\hline
\end{tabular}

Evaluasi hasil pengujian berdasarkan Standar Spesifikasi yang telah ditentukan. Spesifikasi Umum 2018 merupakan spesifikasi teknik pekerjaan jalan dan jembatan.

Beberapa pengujian karakteristik seperti analisa saringan, pengujian kadar lumpur, pengujian lolos saringan No. 200, dan pemeriksaan partikel pipih dan lonjong dapat dilakukan penumbukan agregat kembali dan melakukan pengujian ulang agar memenuhi standar spesifikasi.

3. Rancangan campuran
Volume 3 No.2, Juni 2021

e-ISSN 2775-4529

p-ISSN 2775-8613

Perancangan campuran dapat dilihat berdasarkan pada ukuran campuran agregat yang telah dipilih seperti ukuran gradasi agregat ideal. Berdasarkan Ukuran agregat terdiri atas 3 fraksi yaitu diantaranya: agregat kasar, agregat halus, dan Filler yang menace pada Standar Bina Marga pada tabel 3 .

\section{Komposisi campuran}

Berikut ini rancangan awal kadar aspal untuk ACBASE:

Kadar aspal efektif min. $\quad=0,6 \%$

Kadar aspal efektif mak $\quad=1,2 \%$

Filler $\quad=5 \%$

Kadar aspal rancangan maks $=8,33 \%$

Kadar aspal rancangan min $=4,17 \%$

Berdasarkan perhitungan kadar aspal diatas maka untuk lapisan AC-BASE maka dapat direncanakan campuran gradasi agregat gabungan agregat, filler,dan aspal maka didapatkan tabel komposisi campuran AC -BASE beserta dengan tabel

Table 3. Rancangan Campuran

\begin{tabular}{c|c|c}
\hline \multirow{2}{*}{$\begin{array}{c}\text { Ukuran ayakan } \\
(\mathrm{mm})\end{array}$} & \multicolumn{2}{|c}{ \% Berat yang Lolos terhadap Total Agregat dalam } \\
& Campuran \\
\cline { 2 - 3 } & Spesifikasi radasi & Rancangan Gradasi Campuran \\
\hline $1 \frac{1}{2}$ & 100 & 100 \\
\hline 1 & $90-100$ & 95 \\
\hline $3 / 4$ & $76-90$ & 83 \\
\hline $1 / 2$ & $60-78$ & 69 \\
\hline $3 / 8$ & $52-71$ & 61,5 \\
\hline 4 & $35-54$ & 44,5 \\
\hline 8 & $23-41$ & 32 \\
\hline 16 & $13-30$ & 21,5 \\
\hline 30 & $10-22$ & 16 \\
\hline 50 & $6-15$ & 10,5 \\
\hline 100 & $4-10$ & 7 \\
\hline 200 & $3-7$ & 5 \\
\hline
\end{tabular}


Tabel 4. Komposisi campuran

\begin{tabular}{|c|c|c|c|c|c|c|}
\hline \multirow{2}{*}{ Material } & \multirow{2}{*}{ Uk .Saringan } & \multicolumn{5}{|c|}{ Kadar Aspal } \\
\hline & & $4,5 \%$ & $5,00 \%$ & $5,50 \%$ & $6,00 \%$ & $6,50 \%$ \\
\hline \multirow{4}{*}{ Agregat Kasar } & $\begin{array}{c}1^{\prime} \\
3 / 4 "\end{array}$ & & & & & \\
\hline & $1 / 2 "$ & 53,63 & 53,42 & 53,21 & 53,00 & 52,79 \\
\hline & $3 / 8 "$ & & & & & \\
\hline & No. 4 & & & & & \\
\hline \multirow{6}{*}{ Agregat Halus } & No.8 & \multirow{6}{*}{37,25} & \multirow{6}{*}{37,00} & \multirow{6}{*}{36,75} & \multirow{6}{*}{36,50} & \multirow{6}{*}{36,25} \\
\hline & No.18 & & & & & \\
\hline & No.30 & & & & & \\
\hline & No.50 & & & & & \\
\hline & No.100 & & & & & \\
\hline & No.200 & & & & & \\
\hline Filler & & 4,63 & 4,58 & 4,54 & 4,50 & 4,46 \\
\hline
\end{tabular}

Tabel 5. Jumlah benda uji

\begin{tabular}{ccc}
\hline $\begin{array}{c}\text { Kadar } \\
\text { Aspal }\end{array}$ & $\begin{array}{c}\text { Marshall } \\
\text { Konvensional }\end{array}$ & $\begin{array}{c}\text { Marshall } \\
\text { Immertion }\end{array}$ \\
\hline $4,50 \%$ & 3 & \\
$5,00 \%$ & 3 & \\
$5,50 \%$ & 3 & 3 \\
$6,00 \%$ & 3 & \\
$6,50 \%$ & 3 & \\
\hline
\end{tabular}

\section{Pengujian Marshall Konvensional}

Dalam Pengujian Marshall Konvensional terdapat 3 tahap yang dapat kita lakukan yaitu pengukuran berat jenis, pengukuran stabilitas dan aliran pengukuran analisis kepadan dan rongga. Beberapa hal yang perlu diperhatikan sebelum melakukan pengujian seperti membersikan dari kotoran organic, minyak, kertas dan sebagainya dan pada setiap sampel yang diuji harus diberikan kode agar dapat mengetahui perbedaan setiap sampel.

\section{Penentuan Kadar aspal optimum}

Setelah menghitung hasil uji Marshall konvensional, tentukan kadar aspal yang optimal dengan menginputkan data thermal mixing table rancangan metode Marshall untuk mengetahui nilai kestabilan, laju alir, berat jenis pencampuran dan berat jenis agregat. Agar tidak terjadi fluktuasi pada kadar aspal yang sesungguhnya perlu menentukan Kadar Aspal Optimum (KAO) yang memiliki nilai stabilitas tinggi.

\section{Uji Marshall Immertion}

Untuk proses pengujian hamper sama dengan pengujian Marshal konversional standar, perbedaannya hanya terdapat pada pengujian marshall immersion dilakukan perendaman selama 24 jam dengan suhu $60{ }^{\circ} \mathrm{C}$. Hasil yang diperoleh rasio kestabilan pengujian ini adalah membandingkan kestabilan sampel uji Marshall setelah direndam dalam penampungan air dalam suhu 60 OC selama 24 jam. dengan perendaman 30 menit yang bisa disebut Stabilitas Marshall Sisa (SMS).

\section{HASIL DAN PEMBAHASAN}

1. Hasil Pengujian Karakteristik Material

a. Karakteristik Agregat

Hasil dari pengujian karakteristik material dapat dilihat pada tabel tabel 6 .

Tabel 6. Hasil pengujian karakteristik agregat

\begin{tabular}{lll}
\hline No. & Percobaan & Hasil \\
\hline 1 & Keausan dengan Mesin Los & \\
& Angels & 13 \\
& Fraksi A & 11,72 \\
& Fraksi B & 8,04
\end{tabular}




\begin{tabular}{|c|c|c|}
\hline & Fraksi D & 15,72 \\
\hline \multirow[t]{4}{*}{2} & & 2,66 \\
\hline & Berat Jenis dan Absorpsi & 2,70 \\
\hline & Agregat Kasar & 2,75 \\
\hline & & 1,26 \\
\hline \multirow[t]{4}{*}{3} & & 2,69 \\
\hline & Berat Jenis dan Absorpsi & 2,72 \\
\hline & Agregat Halus & 2,78 \\
\hline & & 1,11 \\
\hline \multirow[t]{13}{*}{4} & Analisa Saringan & \\
\hline & $1 "$ & 100 \\
\hline & $3 / 4 "$ & 95,06 \\
\hline & $1 / 2 "$ & 88,69 \\
\hline & $3 / 8 "$ & 78,34 \\
\hline & No.4 & \\
\hline & No.8 & 59,74 \\
\hline & No. 16 & 40,62 \\
\hline & No.30 & 25,72 \\
\hline & No.50 & 18,71 \\
\hline & No. 100 & 12,43 \\
\hline & No.200 & 8,29 \\
\hline & PAN & 6,16 \\
\hline 5 & $\begin{array}{l}\text { Uji Material Lolos Saringan } \\
\text { no. } 200\end{array}$ & 8,00 \\
\hline \multirow[t]{2}{*}{6} & Sand Equivalent & 97,56 \\
\hline & Nilai Setara Pasir & 2,44 \\
\hline 7 & $\begin{array}{l}\text { Kelekatan } \\
\text { Terhadap Aspal }\end{array}$ & $>98$ \\
\hline 8 & $\begin{array}{l}\text { Pemeriksaan Berat Jenis } \\
\text { Filler semen }\end{array}$ & 3,09 \\
\hline
\end{tabular}

Hasil Analisa saringan seperti pada gambar 2 menunujukkan gradasi berada diantara batas atas dan batas bawah, dimana gradasi agregat lebih mendekati batas atas yang menunjukkan gradasi agregat lebih halus, sebaliknya apabila dominan ke arah batas bawah berarti agregat yang lolos lebih banyak agregat kasarnya. Uji material lolos saringan No. 200 memenuhi persyaratan dengan nilai 8.00 dar $10 \%$.

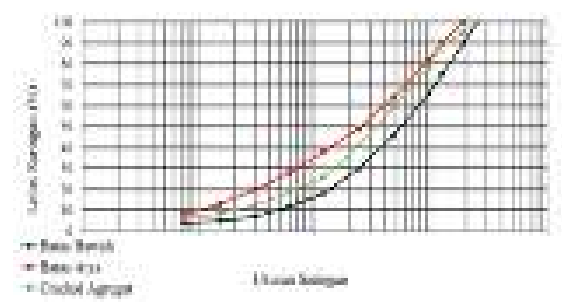

Gambar 2. Hasil pengujian Analisa saringan
Hasil Pemeriksaan Kadar Lumpur Agregat Halus diperoleh hasil rata- rata untuk nilai setara dengan pasir adalah 97,56 \% dan kadar lumpur $2,44 \%$ lolos syarat Bina Marga2018. Pengujian Partikel Kepipihan dan Kelonjongan Agregat Kasar telah memenuhi spesifikasi Umum Bina Marga 2018 yaitu maksimal $10 \%$. Pemeriksaan kelekatan suatu agregat pada aspal didapatkan telah mencapai $98 \%$ dimana telah memenuhi standar Bina Marga yaitu dengan standar 95\%.

\section{b. Karakteristik aspal}

Hasil pengujian penetrasi adalah $66,7 \%$ yang telah memenuhi interval yaitu batas $60 \%-70 \%$. Hasil Pemeriksaan titik lembek aspal didapatkan niiai rata-rata $52,0^{\circ} \mathrm{C}$ yang memenuhi syarat $\geq 48^{\circ}$ C. Hasil uji Titik Nyala dan Titik Bakar didapatkan nilai rata-rata $2900 \mathrm{C}$ telah memenuhi syarat $\geq$ 2320 C. Hasil Pemeriksaan Berat Jenis Aspal yang telah diperoleh sebesar 1,105 sehingga telah memenuhi standar yaitu $\geq 1,0$. Hasil Pemeriksaan daktilitas yang telah diperoleh sebesar 150 dan telah memenuhi standar yaitu $\geq 100$. Hasil pemeriksaan penetrasi Thin Film Oven Test diperoleh sebesar 84,7 \%dimana telah memenuhi standar yang telah ditentukan yaitu $\geq 54 \%$. Dan untuk hasil pemeriksaan kehilangan berat aspal didapatkan nilai rata-rata 0,434 yang memenuhi syarat $\leq 0,8$. Hasil analisis Bulk Spesifik Graviy Specific Graviity

Spesimen dibuat dengan kadar aspal AC -BASE adalah: $4.50 \%, 5.00 \%, 5.50 \%, 6.00 \%, 6.50 \%$. Tabel 7 berikut mencantumkan hasil yang diperoleh:

\section{Karakteristik campuran}

Tabel 7 adalah rekap hasil pemeriksaan karakteristik campuran untuk pengujian marshall konvensional.

\section{a. Void in Mineral (V I M)}

Pada gambar 3 menunjukkan bahwa penggunaan kadar pada aspal 4,5 \% - 6,5 \% ACBASE diperoleh nilai VIM. Pada kadar 4,5 \% - 6,5 $\%$ mengalami penurunan dari $4,56 \%-3,43 \%$ telah lolos persyaratan 
Tabel 7. Bulk Spesific Gravity and Efective Specific Graviity.

\begin{tabular}{cccccc}
\hline \multirow{2}{*}{ Nilai } & \multicolumn{5}{c}{ Kadar Aspal (\%) } \\
\cline { 2 - 6 } & 4,50 & 5,00 & 5,50 & 6,00 & 6,50 \\
\hline Bulk Specific Graviity & 2,82 & 2,83 & 2,85 & 2,86 & 2,88 \\
Bulk Specific Graviity & 2,86 & 2,88 & 2,89 & 2,91 & 2,92 \\
\hline
\end{tabular}

Tabel 8. Karakteristik campuran

\begin{tabular}{cccccc}
\hline $\begin{array}{c}\text { Kadar Aspal } \\
(\%)\end{array}$ & $3-5(\%)$ & Min 800 $(\mathrm{kg})$ & Min 65 $(\%)$ & II-IV $(\mathrm{mm})$ & Min 14 (\%) \\
\cline { 2 - 6 } & VIM & Stabilitas & VFB & Flow & VMA \\
\hline 4,50 & 4.56 & 2010,24 & 68,39 & 4,10 & 14,43 \\
5.00 & 4.27 & 2462,30 & 72,24 & 3.60 & 15,39 \\
5,50 & 3,6 & 2669,93 & 75,73 & 3.40 & 16,33 \\
6.00 & 3.63 & 2459,50 & 78,96 & 3.60 & 17,25 \\
6,50 & 3.43 & 2292,01 & 81,23 & 4,30 & 18,28 \\
\hline
\end{tabular}

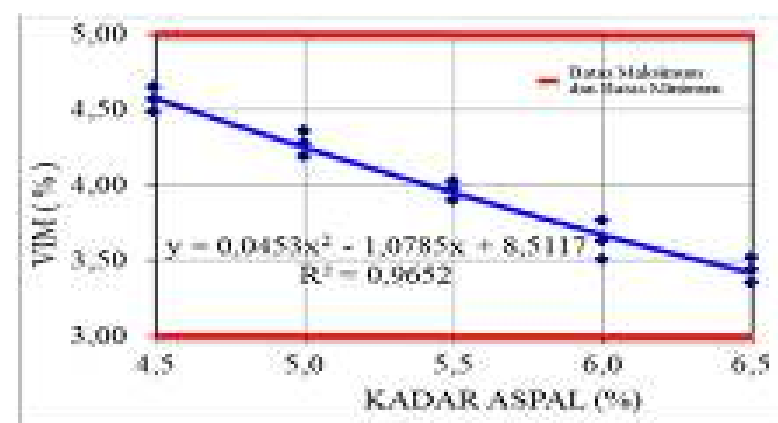

Gambar 3. Hubungan antara Kadar Aspal dengan VIM

\section{b. Stabilitas}

Dari gambar 4 dapat diketahui penambahan kadar aspal $5 \%$ sampai dengan $5.5 \%$ nilai stablitas campuran meningkat sedangkan penambahan $6 \%$ sampai dengan $7 \%$ nilai stabilitas campuran menurun. Penurunan nilai stabilitas masih dalam batas yang ditentukan spesifikasi

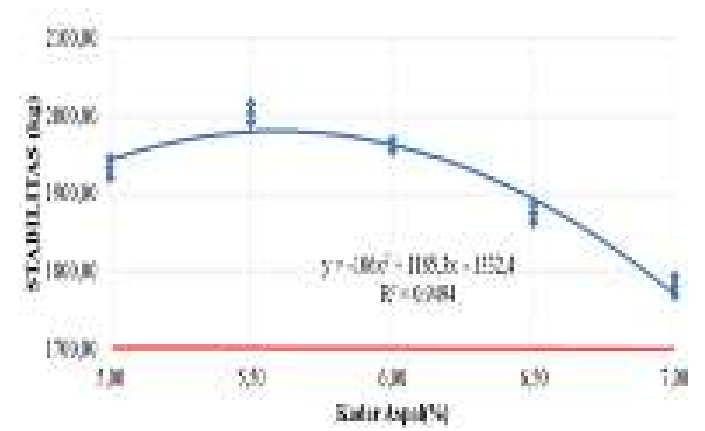

Gambar 4. Hubungan antara Stabilitas dengan kadar aspal

\section{c. Voids Filled with Bitumen (VFB)}

Berdasarkan Grafik yang diperoleh dapat dilihat bahwa nilai VFB yang diperoleh yaitu $70.38 \%$ sampai dengan $82.51 \%$ dan telah memenuhi standar spesifikasi. 
Paulus Civil Engineering Journal

Jurnal Teknik Sipil UKI-Paulus Makassar

https://doi.org/10.52722/pcej.v3i2.3220

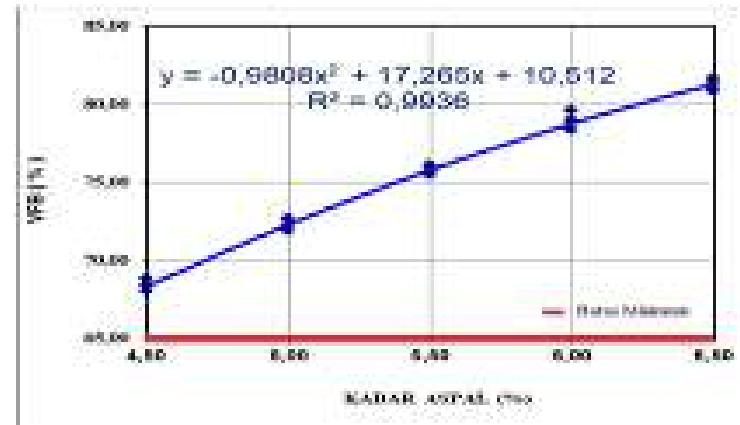

Gambar 5. Hubungan antara VFB dengan kadar aspal

\section{d. Flow}

Dari gambar 6 didapatkan nilai flow dari $4,10 \mathrm{~mm}$ - 4,30 mm yang telah memenuhi standard spesifikasi bina marga.

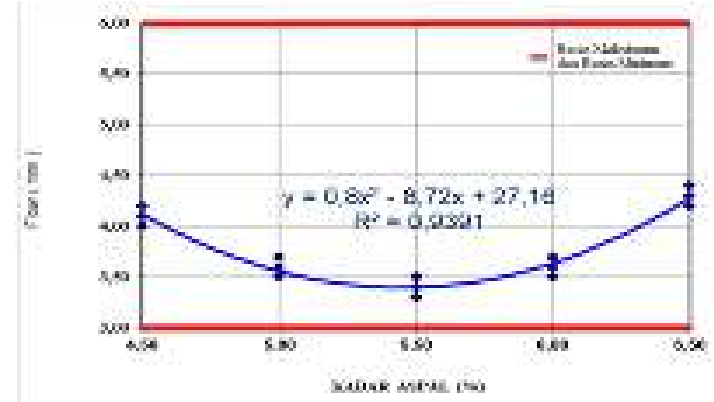

Gambar 6. Grafik Hubungan Kadar Aspal dengan Flow

\section{a. Voids in Mineral Agregate (VMA)}

Dari gambar 7 didapatkan nilai 14,43\% $18,28 \%$ untuk campuran AC-BASE nya telah memenuhi standard spesifikasi bina marga.

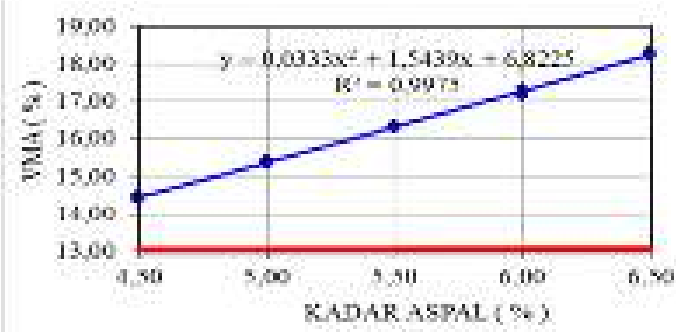

Gambar 7. Grafik Hubungan antara Kadar Aspal dengan VMA

\section{Penentuan Kadar Aspal Optimum}

Kadar aspal praktis yang sangat rentang kadar aspal yaitu sebesar $4,5 \%-6,5 \%$ dan telah memenuhi persyaratan untuk campuran AC-
Volume 3 No.2, Juni 2021

e-ISSN 2775-4529

p-ISSN 2775-8613

BASE. Maka pada campuran AC-BASE dipilih yang memiliki nilai dikarenakan fungsi campuran AC -BASE Artinya, ia menerima beban lalu lintas dan meneruskannya ke lapisan Sub Grade.

\section{Stabilitas Marshall Sisa}

Kadar aspal optimum yang digunakan adalah 5,5 $\%$ pada campuran AC- BASE dengan nilai stabilitas marshall sisa yaitu $97,10 \%$ yang telah memenuhi syarat spesifikasi dan dapat agregat sungai seriti dapat digunakan dalam campuran AC-BASE.

Tabel 8. Hasil pengujian IKS

\begin{tabular}{cccc}
\hline $\begin{array}{c}\text { Kadar AspaI } \\
(\%)\end{array}$ & \multicolumn{2}{c}{ Nilai Stabilitas } & SMS \\
\hline & lmmersion & KonvensionaI \\
\hline 5,50 & 2557,01 & 2634,49 & 97,06 \\
5,50 & 2634,49 & 2711,98 & 97,14 \\
5,50 & 2582,83 & 2660,32 & 97,09 \\
\hline Rata-rata & 2591,44 & 2668,93 & 97,10 \\
\hline
\end{tabular}

\section{KESIMPULAN}

Hasil pengujian karakteristik agregat yang diperoleh dari Kecamatan Lamasi Timur Kabupaten Luwu, Karakteristik aspal dan Berat Jenis Filler untuk campuran AC-BASE telah lolos syarat untuk perkerasaan jalan khususnya lapisan perkerasan campuran AC-BASE.

Komposisi campuran AC-BASE menggunakan agregat dari sungai Seriti Kabupaten Luwu yaitu agregat kasar $53,21 \%$, agregat halus (Pasir) $36,75 \%$, Filler $4,54 \%$ diperoleh kadar aspal optimum sebesar 5,5\%. Pada rancangan ini kadar aspal optimum yang telah diperoleh tidak perlu ditambahkan ataupun dikurangi karena kekuatan dan kelenturannya telah memenuhi syarat spesifikasi Bina Marga 2018.

Dari hasil pengujian campuran AC- BASE yang telah Iolos uji Marshall Konvensional dan Nilai Marshall Immertion telah memenuhi standar spesifikasi yang telah di tentukan pada tahun 2018 yaitu $97,10 \%$ dengan syarat $>90 \%$.

\section{DAFTAR PUSTAKA}

[1] F. L. Allo, Irianto, Elisabeth, dan Alpius, "Pemanfaatan Agregat Sungai Wanggar Kabupaten Nabire Sebagai Bahan 
Campuran AC-WC danAC-BC," Paulus Civ. Eng. J., vol. 1, no. 2, hlm. 28-36, 2019.

[2] I. S. K. Sosang, Alpius, dan Elisabeth, "Pemanfaatan Agregat Sungai Mawa Kecamatan Cendana dalam Campuran ACWC," Paulus Civ. Eng. J., vol. 2, no. 1, hlm. 53-57, 2020.

[3] R. Rachman, "Pemanfaatan Batu Gunung Bottomale Toraja Utara sebagai Campuran Laston," J. Tek. Sipil Dan Teknol., vol. 6, no. 1, hlm. 20-30, 2020.

[4] Irpan, R. Mangontan, dan Alpius, "Pemanfaatan Batu Gunung Ambeso pada Campuran AC-Base," Paulus Civ. Eng. J., vol. 2, no. 1, hlm. 58-62, 2020.

[5] N. A. Salmon, Alpius, dan C. Kamba, "Pemanfaatan Batu Gunung Posi'padang Balla Kabupaten Mamasa Sebagai Campuran AC-BC," Paulus Civ. Eng. J., vol. 2, no. 2, hlm. 77-84, 2020.

[6] G. P. Palimbunga, R. Rachman, dan Alpius, "Penggunaan Agregat Sungai Batu Tiakka' dalam Campuran AC-BC," Paulus Civ. Eng. J., vol. 2, no. 2, hlm. 112-118, 2020.

[7] A. D. Sandabunga, N. Ali, dan R. Rachman, "Karakteristik Campuran SMA Kasar Menggunakan Batu Sungai Sa'dan Kecamatan Sesean Toraja Utara," Paulus Civ. Eng. J., vol. 2, no. 4, hlm. 282-288, 2020.

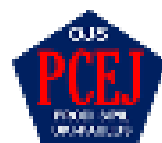

Volume 3 No.2, Juni 2021 e-ISSN 2775-4529 p-ISSN 2775-8613

[8] R. A. Jansen, N. Ali, dan R. Rachman, "Pemanfaatan Batu Sungai Sa'dan Toraja Utara Sebagai Campuran Stone Matrix Asphalt Halus," Paulus Civ. Eng. J., vol. 2, no. 4, hlm. 314-320, 2020.

[9] R. Rachman, "Karakteristik Campuran HRS - BASE Menggunakan Bubuk Dolomit Sebagai Filler," dalam Konfrensi Nasional Teknik Sipil Ke 13, Banda Aceh, Sep 2019, vol. 1, hlm. 420-430.

[10] J. Tandibua, R. Rachman, dan J. Tanijaya, "Study of Laston BC Durability and Permeability Using Coconut Shell Addition Materials," dalam The 3rd International Conference on Civil and Environmental Engineering (ICCEE), Bali, Indonesia, 2020, vol. 419, doi: 10.1088/17551315/419/1/012035.

[11] D. P. Randelabi, R. Rachman, dan Alpius, "Pengujian Karakteristik Campuran HRSBase Menggunakan LGASebagai Pengganti Aspal Minyak," Paulus Civ. Eng. J., vol. 2, no. 1, hlm. 16-22, 2020.

[12] Direkorat Jenderal Bina Marga, Spesifikasi Umum Bina Marga 2018 untuk Pekerjaan Konstruksi Jalan dan Jembatan Divisi 6. Jakarta: Kementerian Pekerjaan Umum dan Perumahan Rakyat, 2018. 